\title{
Imperatorin inhibits allergic airway inflammatory reaction and mucin secretion in ovalbumin-induced asthmatic rats
}

\author{
Qiang $\mathrm{Li}^{1}$, Wu Ding ${ }^{1}$, Yu-zhi Gao ${ }^{1}$, Yu-lin $\mathrm{Li}^{1}$, Li-bing Jiang ${ }^{1}$, Yuan Jiang ${ }^{2 *}$ \\ ${ }^{1}$ Emergency Department, Second Affiliated Hospital of Zhejiang University School of Medicine, Hangzhou, Zhejiang 310009, \\ ${ }^{2}$ Department of Pulmonology, Children's Hospital, Zhejiang University School of Medicine, Hangzhou, Zhejiang 310003, China \\ *For correspondence: Email: yuanj212@126.com; Tel: 0571-87783921; Fax: 0571-87068001
}

\begin{abstract}
Purpose: To study the therapeutic effects of imperatorin (IPT) on allergic asthma induced by ovalbumin in rats.

Methods: Asthma was established in rats by injection of ovalbumin (OVA), and IPT (20, 40 and 80 $\mathrm{mg} / \mathrm{kg}$ ) was administered orally for 21 days. Inflammatory cells and cytokines were determined in the bronchoalveolar lavage fluid (BALF); IgE and histamine in the serum were also determined. Furthermore, MUC-5AC expression in the lung tissue was determined by Western blot assay.

Results: Treatment with IPT (20, 40 and $80 \mathrm{mg} / \mathrm{kg})$ decreased inflammatory cells including eosinophils $(p<0.01)$, neutrophils $(p<0.05)$, Iymphocytes $(p<0.01)$ and macrophages $(p<0.01)$. In addition, the four inflammatory cytokines finterleukin (IL) -4, IL-6, IL-13 and tumor necrosis factor (TNF)- $\alpha$ \} were significantly decreased by treatment with IPT $(20,40$ and $80 \mathrm{mg} / \mathrm{kg})$ dose-dependently $(p<0.01)$. Furthermore, MUC5AC in lung tissues was significantly down-regulated by treatment with IPT (20, 40 and $80 \mathrm{mg} / \mathrm{kg}, p<0.01$ ) in a dose-dependent fashion.

Conclusion: The results show that IPT exerts notable therapeutic effects on allergic asthma in rats via suppression of IgE, histamine, inflammatory cells and cytokines, and also by down-regulating MUC5AC.
\end{abstract}

Keywords: Imperatorin, Allergic asthma, Inflammatory cytokines, MUC5AC expression, Eosinophils, Neutrophils, Lymphocytes

Tropical Journal of Pharmaceutical Research is indexed by Science Citation Index (SciSearch), Scopus, International Pharmaceutical Abstract, Chemical Abstracts, Embase, Index Copernicus, EBSCO, African Index Medicus, JournalSeek, Journal Citation Reports/Science Edition, Directory of Open Access Journals (DOAJ), African Journal Online, Bioline International, Open-J-Gate and Pharmacy Abstracts

\section{INTRODUCTION}

In recent years, allergic asthma with an incidence rate of $4.3 \%$ in the world has become a common disease affecting the normal life of millions of children and adults $[1,2]$. It is estimated that asthma causes over 300,000 deaths in the whole world every year [1-3]. Asthma is a chronic disease with complex pathology and characterized by serious airway inflammatory reactions, excessive phlegm and shortness of breath, etc. [4]. Currently, available drugs can temporary control or relieve the asthma symptoms, however radical cure of asthma seems very difficult. Furthermore, taking these drugs over a long term could cause several annoying adverse reactions $[5,6]$.

Herbal medicines and natural plant-derived agents are important sources for discovering new effective drugs with low toxicity [7]. Imperatorin (IPT, Figure 1) is a natural constituent commonly existing in plants of the Umbelliferae family, such as Peucedanum praeruptorum and Angelica dahurica [8]. IPT shows a broad pharmacological activities including anti-seizure, vasodilatation, antitumor, antimicrobial, anti-inflammatory, and analgesic effects [8-10]. However, to the best of 
our knowledge, there is no information on the effects of IPT on allergic asthma. Thus, in this study, the therapeutic effect of IPT on allergic asthma was evaluated based on an ovalbumin (OVA) -induced asthma model in rats, and its pharmacological mechanisms were furthermore explored.<smiles>CC(C)=CCOc1c2occc2cc2ccc(=O)oc12</smiles>

Figure 1: Chemical structure of IPT

\section{EXPERIMENTAL}

\section{Animals}

Male Sprague Dawley (SD) rats $(200 \pm 20 \mathrm{~g})$ were purchased from the Shanghai Laboratory Animal Research Center (Shanghai, China). The animals and experimental protocols were handled according to the Declaration of Helsinki promulgated in 1964 as amended in 1996 [10], and approved by the Animal Care and Use Committee of Zhejiang University School of Medicine (approval no. An-2015-0393\#).

\section{Chemicals and reagents}

Imperatorin (IPT) was purchased from Chengdu Pure Chem-Standard. Co. Ltd. Chengdu, China; commercially enzyme-linked immunosorbent assay (ELISA) kits for interleukin (IL) -4, IL-13 and tumor necrosis factor (TNF)- $\alpha$ were purchased from Invitrogen, Carlsbad, CA, USA and ELISA kits for IgE, IL-6, and histamine were obtained from eBioscience, Shanghai, China. OVA, pentobarbital and aluminum hydroxide were purchased from Sigma-Aldrich, St. Louis, MO. U.S.A. BCA protein assay reagent and horseradish peroxidase-conjugated secondary antibody were purchased from Beyotime, Nanking, China. Primary antibodies used in western blotting assay for MUC 5AC and $\beta$-actin were purchased from Abcam, Cambridge, UK.

\section{Animal model and experimental protocol}

A total of $50 \mathrm{SD}$ rats were randomly divided into five groups $(n=10)$ : normal group, control group, and IPT groups $(20,40$ and $80 \mathrm{mg} / \mathrm{kg})$. The OVA-induced asthma rats were prepared according to the method described by Lee et al with minor modification [11]. Briefly, each SD rat in control and IPT groups were immunized by intraperitoneal injection (ip) of a mixture of $20 \mathrm{mg}$ OVA and $2 \mathrm{mg}$ aluminum hydroxide at 1 and 7 days. Furthermore, rats in the control and IPT groups received an airway challenge with $1 \%$ (w/v) OVA solution for 20 min using an ultrasonic nebulizer (Yuyao 402A, Nanking, China) from day 17 to day 21 after the initial sensitization. For the normal group, rats underwent the same sensitization procedures with saline instead of OVA. During this process, normal and control rats were orally treated with saline continuously from the first OVA injection to the end of the experiment $(20 \mathrm{ml} / \mathrm{kg})$, and rats in the IPT groups were administered orally with IPT at doses of 20, 40 and $80 \mathrm{mg} / \mathrm{kg}$, respectively.

After $48 \mathrm{~h}$ of the final challenge, blood samples of the rats were collected under pentobarbital (50 $\mathrm{mg} / \mathrm{kg}$, ip) by abdominal aortic blood sampling, then rats were sacrificed to obtain the bronchoalveolar lavage fluid (BALF) and inflammatory cell numbers were determined by counting cells with a hemocytometer. In addition, the lung tissues were also collected for further western blot assay. All the samples were stored at $-70{ }^{\circ} \mathrm{C}$ before using.

\section{Determination of $\lg E$ and histamine in plasma}

Blood was centrifuged (3000 rpm) for $10 \mathrm{~min}$ to obtain plasma samples. Then, the levels of lgE and histamine were determined using commercial ELISA kits according to the manufacturer's instructions.

\section{Determination of inflammatory cytokines in BALF}

The supernatants of the BALF were obtained and the levels of inflammatory cytokines in BALF including TNF- $\alpha, \quad \mathrm{IL}-4, \mathrm{IL}-6$ and IL-13 were determined using commercial ELISA kits according to the manufacturer's instructions.

\section{Western blot assay}

Lung tissues were homogenized and then centrifuged at $3000 \mathrm{rpm}$ for $30 \mathrm{~min}$ at $4{ }^{\circ} \mathrm{C}$, and subsequently total proteins were extracted from the supernatants. After that, protein concentration was determined using a BCA protein assay reagent. Then, equal amounts of total lung proteins $(30 \mu \mathrm{g})$ were heated at $100{ }^{\circ} \mathrm{C}$ for $5 \mathrm{~min}$ and subsequently loaded onto $8 \%$ sodium dodecyl sulfate polyacrylamide gel electrophoresis gels (SDS/PAGE), followed by blotting to a PVDF membrane. Nonspecific 
binding sites of the PVDF membranes were blocked with $5 \%$ skimmed milk for $1 \mathrm{~h}$. After that, the PVDF membranes were incubated with the primary antibody for MUC-5AC and $\beta$-actin at 4 ${ }^{\circ} \mathrm{C}$ overnight. The membranes were washed three times with TBST, and then incubated with horseradish peroxidase-conjugated secondary antibody for $1 \mathrm{~h}$ at room temperature. The target protein bands on the PVDF membranes were visualized using chemiluminiscence.

\section{Statistical analysis}

Data are presented as mean \pm standard deviations (SD). Statistical comparisons were made by one-way analysis of variance (ANOVA) using SPSS software (version 15.0, USA), followed by Dunnett multiple comparison test. $P$ $<0.05$ was set as the significance level.

\section{RESULTS}

\section{Effect of IPT on inflammatory cells in BALF}

In order to determine the inhibitory effects of IPT on airway inflammatory reactions in the development of allergic asthma, we analysed the four inflammatory cells in BALF including eosinophils, neutrophils, lymphocytes and macrophages. As can be seen from Figure 2, BALF of OVA-challenged rats exhibited significant increase in these four inflammatory cells $(p<0.01)$. However, treatment with IPT at doses of 20,40 and $80 \mathrm{mg} / \mathrm{kg}$ decreased the inflammatory cells including eosinophils $(p<$ $0.01)$, lymphocytes $(p<0.01)$ and macrophages $(p<0.01)$, a dose-dependent manner. In addition, IPT (40 and $80 \mathrm{mg} / \mathrm{kg}$ ) also showed a significant inhibitory effects on neutrophils $(p<$ $0.05, p<0.01$ ).

\section{Effect of IPT on levels of serum IgE and histamine}

Results of the serum IgE and histamine levels in OVA-induced asthmatic rats are shown in Figure 3. The levels of serum $\operatorname{lgE}$ and histamine in OVA-challenged rats were increased compared with normal rats $(p<0.01)$. Furthermore, this result also demonstrated that the increased serum IgE and histamine of OVA-challenged rats could be significantly decreased by treating with IPT $(20,40$ and $80 \mathrm{mg} / \mathrm{kg})$ dose-dependently compared with the control rats $(p<0.05)$.
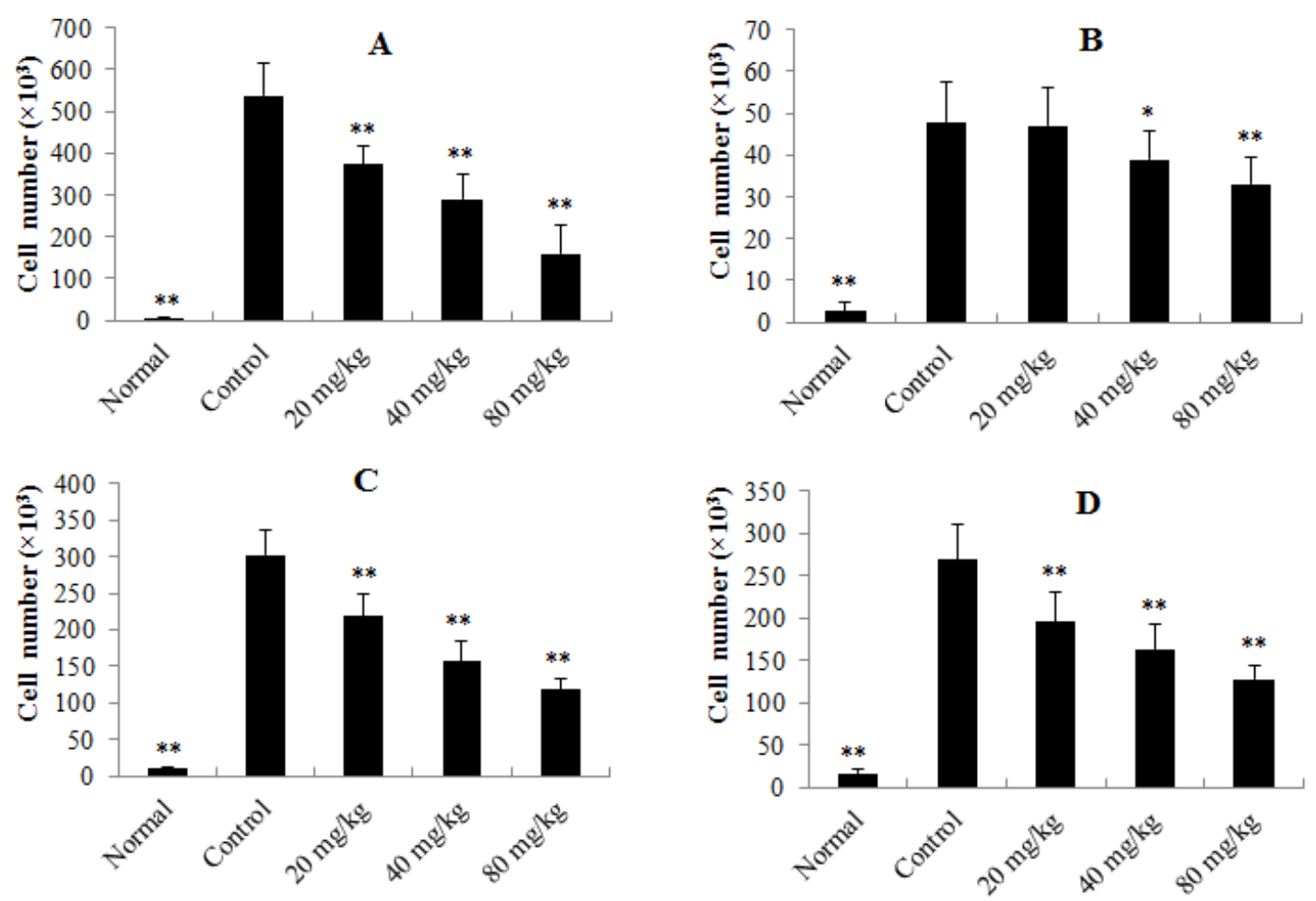

Figure 2: Effect of IPT on inflammatory cells in BALF. A-D represented eosinophils, neutrophils, lymphocytes and macrophages, respectively. Data were expressed as mean $\pm \operatorname{SD}(n=10) ;{ }^{*} p<0.05,{ }^{* *} p<0.01$, compared with the control group 

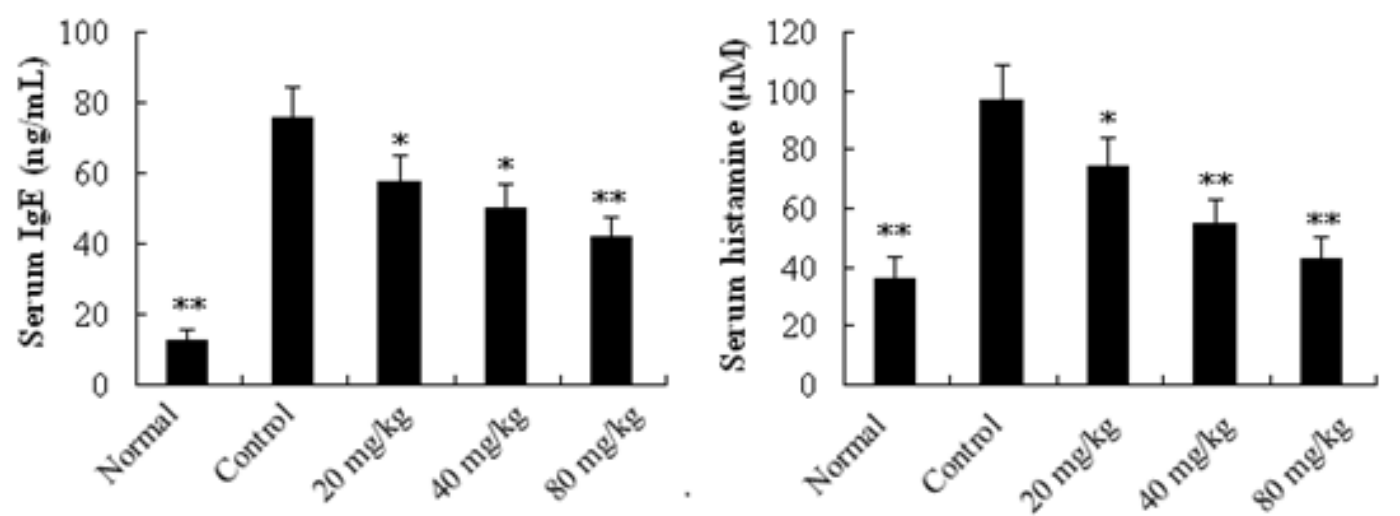

Figure 3: Effect of IPT on serum IgE and histamine. Data were expressed as mean $\pm \mathrm{SD}(\mathrm{n}=10) ;{ }^{*} p<0.05,{ }^{* *} p$ $<0.01$, compared with the control group
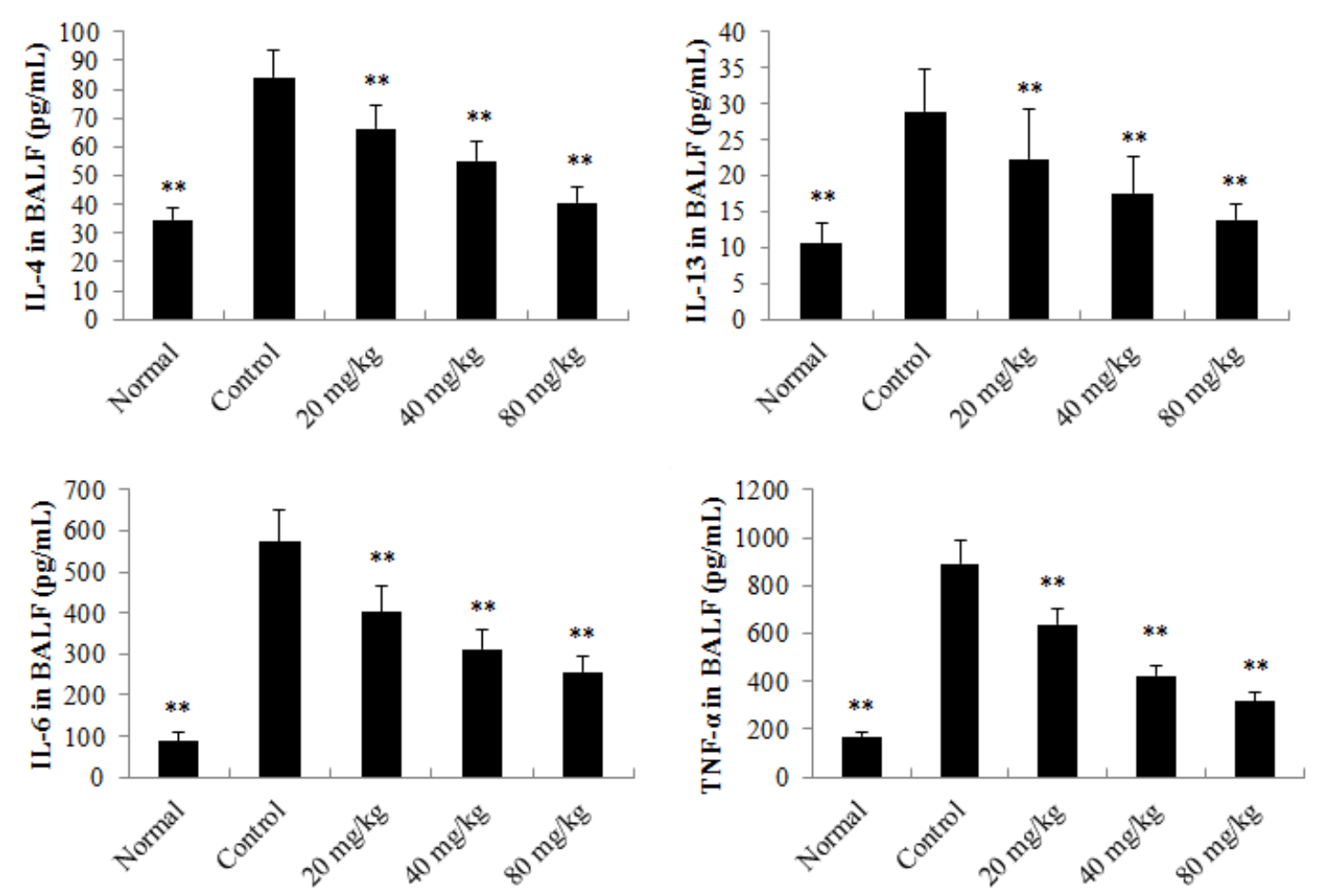

Figure 4: Effect of IPT on inflammatory cytokines in BALF. Data were expressed as mean \pm SD $(n=10) ;{ }^{*} p<$ $0.05,{ }^{* *} p<0.01$, compared with the control group

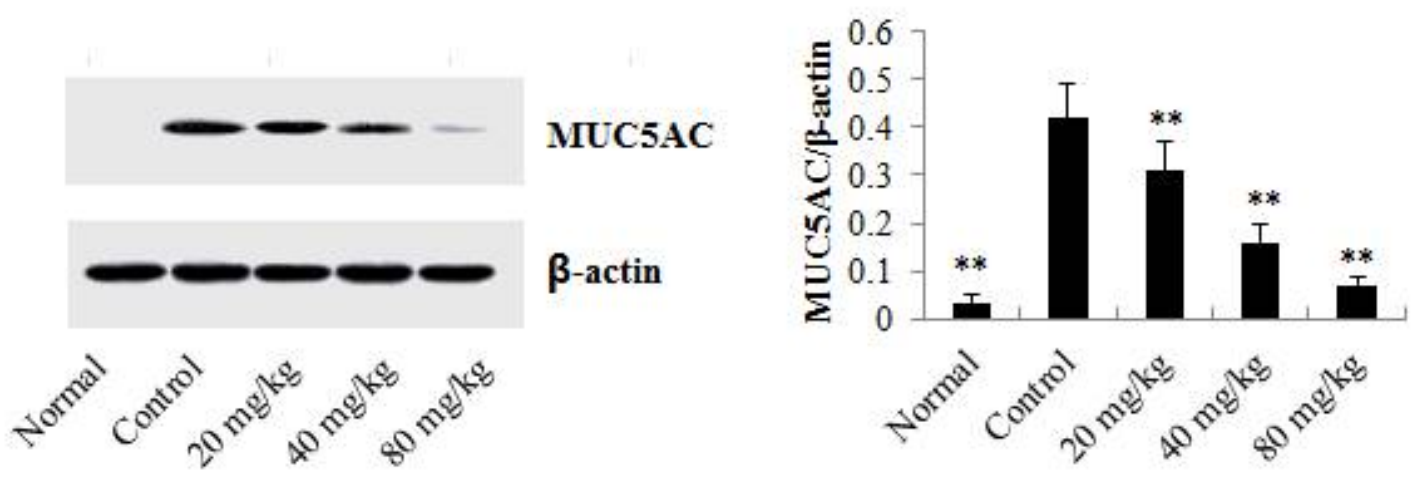

Figure 5: Effect of IPT on MUC5AC protein in lung tissues. Data were expressed as mean \pm SD $(n=4)$; ${ }^{*} p<$ $0.05,{ }^{* *} p<0.01$, compared with the control group 


\section{Effect of IPT on inflammatory cytokines in BALF}

As shown in Figure 4, after injection of OVA for 3 days, all the test inflammatory cytokines significantly increased including IL-4, IL-13, IL-6 and TNF- $\alpha(p<0.1)$, compared with the normal rats. However, it is interesting that all the four inflammatory cytokines were significantly decreased by treatment with IPT at doses of 20, 40 and $80 \mathrm{mg} / \mathrm{kg}(p<0.01)$ dose-dependently, compared with the control rats.

\section{Effect of IPT on MUC 5AC expression in lung tissues}

Furthermore, to explore the possible pharmacological mechanism, whether IPT downregulates MUC 5AC expression in lung tissues of OVA-challenged rats was investigated using western blotting assay. As can be seen from Figure 5, MUC5AC in rats' lung tissues could be sharply up-regulated by challenging with OVA ( $p$ $<$ 0.01). Furthermore, results of the present research demonstrated that MUC5AC could be significantly down-regulated by treatment with IPT at 20,40 and $80 \mathrm{mg} / \mathrm{kg}(p<0.01)$ dosedependently, compared with the control rats.

\section{DISCUSSION}

In the present investigation, the potential therapeutic effects of IPT on allergic asthma were determined using an OVA-induced rat model for the first time. The results showed that IPT inhibited lgE, histamine, and inflammatory cells and cytokines in OVA-challenged rats, as well as down-regulated MUC5AC expression in lung tissue.

Inflammatory reaction is an important cause in the development of asthma, and previous reports also indicated that anti-inflammatory drugs could be beneficial for treating or relieving asthma symptoms [12,13]. In this study, the results showed that IPT possessed significant antiinflammatory effects on airway inflammation induced by OVA via suppression of both inflammatory cells (eosinophils, neutrophils, lymphocytes and macrophages) and cytokines (IL-4, IL-13, IL-6 and TNF- $\alpha$ ). Furthermore, previous researches indicated that asthma is closely related to the proliferation of allergenspecific type II T helper (Th2) lymphocyte, leading to the excessive releases of Th2 cytokines such as IL-4, and IL-13 [14,15]. Thus, suppression of IL-4 \& IL-13 might be an important mechanism for the therapeutic effects of IPT.
IgE and histamine are two important reasons for the development of allergic diseases including eczema, allergic rhinitis and asthma, etc, and previous researches also indicated that $\operatorname{lgE}$ and histamine are also important targets for treating allergic diseases [16]. Interestingly, the present results showed that IPT could effectively decrease the serum levels of $\lg E$ and histamine. It has been reported that hypersecretion of MUC5AC in airway epithelial cells is an important characteristic of asthma and other mucus hypersecretion diseases $[17,18]$. Downregulation of MUC5AC is a feasible way for the treatment of hypersecretion diseases. In addition, it has been reported that TNF- $\alpha$, IL-4 and IL-13 play important roles in the release of MUC5AC [19]. The present results demonstrated that IPT could effectively suppress not only TNF- $\alpha$, IL-4 \& IL-13 but also MUC5AC.

\section{CONCLUSION}

The findings of the present investigation demonstrate that IPT possesses effective therapeutic effects on allergic asthma in a rat model via suppression of $\operatorname{lgE}$, histamine, inflammatory cells and cytokines, as well as by down-regulation of MUC5AC in OVA-induced allergic asthmatic rats.

\section{DECLARATIONS}

\section{Acknowledgement}

Authors were very grateful to Zhejiang University School of Medicine for supporting this work.

\section{Conflict of Interest}

No conflict of interest associated with this work.

\section{Contribution of Authors}

The authors declare that this work was done by the authors named in this article and all liabilities pertaining to claims relating to the content of this article will be borne by them.

\section{Open Access}

This is an Open Access article distributed under the terms of the Creative Commons Attribution License, which permits unrestricted use, distribution, and reproduction in any medium, provided the original work is properly credited. 


\section{REFERENCES}

1. Loftus PA, Wise SK. Epidemiology of asthma. Curr Opin Otolaryngol Head Neck Surg 2016; doi: 10.1097/MOO.0000000000000262.

2. Szefler SJ. Advances in pediatric asthma in 2013: coordinating asthma care. J Allergy Clin Immunol 2014; 133: 654-661.

3. Feldman AS, He Y, Moore ML, Hershenson MB, Hartert TV. Toward primary prevention of asthma: reviewing the evidence for early-life respiratory viral infections as modifiable risk factors to prevent childhood asthma. Am J Respir Crit Care Med 2015; 191: 34-44.

4. Holt PG, Sly PD. Viral infections and atopy in asthma pathogenesis: new rationales for asthma prevention and treatment. Nat Med 2012; 18: 726-735.

5. Olin JT, Wechsler ME. Asthma: pathogenesis and novel drugs for treatment. BMJ 2014; 349: g5517.

6. Dong F, Wang CB, Duan JY, Zhang WY, Xiang DJ, Li MY. Puerarin attenuates ovalbumin-induced lung inflammation and hemostatic unbalance in rat asthma model. Evid Based Complement Alternat Med 2014; 2014: 726740

7. Liu $P$, Yang $H$, Long $F$, Hao HP, Xu X, Liu Y, Shi XW, Zhang $D D$, Zheng HC. Bioactive equivalence of combinatorial components identified in screening of an herbal medicine. Pharm Res 2014; 31:1788-1800.

8. Liu XX, Cao W, Wang SW. Method of extraction and isolation of imperatorin and its advances in pharmacology. Progr Moder Blomed 2010; 10: 3954 3956.

9. Budzynska B, Boguszewska-Czubara A, Kruk-Slomka M. Effects of imperatorin on scopolamine-induced cognitive impairment and oxidative stress in mice. Psychopharmacol (Berl) 2015; 232:931-942.
10. World Medical Organization. Declaration of Helsinki. British Medical Journal (7 December) 1996; 313(7070):1448-1449.

11. Lee MY, Shin IS, Jeon WY, Lim HS, Kim JH, Ha H. Pinellia ternata Breitenbach attenuates ovalbumininduced allergic airway inflammation and mucus secretion in a murine model of asthma. Immunopharmacol Immunotoxicol 2013; 35: 410-418.

12. Shin IS, Lee MY, Jeon WY, Shin NR, Seo CS, Ha H. EBM84 attenuates airway inflammation and mucus hypersecretion in an ovalbumin-induced murine model of asthma. Int J Mol Med 2013; 31: 982-928.

13. Busse WW, Lemanske RF. Asthma. N Engl J Med 2001; 344: 350-362.

14. Lazaar AL, Panettieri RA. Pathogenesis and treatment of asthma: recent advances. Drug Discov Today 2004; 1:111-116.

15. Li KM, Tang HQ, Dou XB, Li XH, Zhu XY, Zheng JY. The association of sputum TSLP, IL-4, IL-5, IL-13 and serum IgE in patients with asthma. J Youjiang Med Univ National 2014; 36: 12-14.

16. Peng $W$, Ming $Q L$, Han $P$, Zhang $Q Y$, Jiang YP, Zheng $C J$, Han T, Qin LP. Anti-allergic rhinitis effect of caffeoylxanthiazonoside isolated from fruits of Xanthium strumarium L. in rodent animals. Phytomedicine 2014; 21: 824-829.

17. Shao MXG, Ueki IF, Nadel JA. Tumor necrosis factorconverting enzyme mediates MUC5AC mucin expression in cultured human airway epithelial cells. PNAS 2003; 100:11618-11623.

18. Wang TS, Lou YJ, Mao YM, Sun YX. Expression of mucin MUC5AC in rats with asthma and mechanisms of anti-inflammatory effects of erythromycin. J Henan Univ Sci Tech (Med Sci) 2007; 25:11-13.

19. Morcillo EJ, Cortijo J. Mucus and MUC in asthma. Curr Opin Pulm Med 2006; 12:1-6. 